\title{
Low Exposure to Direct Oral Anticoagulants Is Associated with Ischemic Stroke and Its Severity
}

\author{
Timolaos Rizos, ${ }^{\mathrm{a}, *}$ Andreas D. Meid, ${ }^{\mathrm{b}, *}$ Andrea Huppertz, ${ }^{\mathrm{b}, *}$ Chris Dumschat, ${ }^{\mathrm{a}}$ Jan Purrucker, ${ }^{\mathrm{a}}$ \\ Kathrin I. Foerster, ${ }^{\mathrm{b}}$ Jürgen Burhenne, ${ }^{\mathrm{b}}$ David Czock, ${ }^{\mathrm{b}}$ Ekkehart Jenetzky, ${ }^{\mathrm{c}, \mathrm{d}}$ Peter A. Ringleb, ${ }^{\mathrm{a}}$ \\ Walter E. Haefeli ${ }^{\mathrm{b}}$ \\ ${ }^{a}$ Department of Neurology, University of Heidelberg, Im Neuenheimer Feld, Heidelberg, Germany \\ ${ }^{b}$ Department of Clinical Pharmacology and Pharmacoepidemiology, University of Heidelberg, Im Neuenheimer Feld, Heidelberg, Germany \\ 'Faculty of Health/School of Medicine, Witten/Herdecke University, Witten, Germany \\ ${ }^{\mathrm{d}}$ Department for Child and Adolescent Psychiatry, Johannes Gutenberg-University, Mainz, Germany
}

Background and purpose In acute stroke patients, plasma concentrations of direct oral anticoagulants (DOAC) at hospital admission only poorly mirror DOAC exposure or the coagulation status at the time of the event. Here, we evaluated whether DOAC exposure and DOAC plasma concentration at the time of transient ischemic attacks (TIA) and ischemic strokes correlate with their likelihood of occurrence.

Methods Prospectively, consecutive DOAC patients with acute ischemic stroke or TIA were included. Admission DOAC plasma concentrations were measured by ultraperformance liquid chromatography-tandem mass spectrometry. Individual DOAC exposure (area under the curve) and DOAC concentrations at event onset were derived from population pharmacokinetic analyses.

Results DOAC exposure was successfully modeled in 211 patients (ischemic stroke 74.4\%, TIA 25.6\%). Compared to published values, 63.0\% had relatively lower DOAC exposure and they more often received lower DOAC doses than recommended (odds ratio [OR], 2.125; 95\% confidence interval $[\mathrm{Cl}$, 1.039 to $4.560 ; P=0.044)$. These patients more likely suffered ischemic strokes than TIA $(O R, 2.411$; $95 \% \mathrm{Cl}, 1.254$ to $4.638 ; P=0.008$ ) and their strokes were more severe (slope, $3.161 ; 95 \% \mathrm{Cl}, 0.741$ to 5.58; $P=0.011)$. Low relative $D O A C$ concentrations at event onset were likewise associated with ischemic strokes $(\mathrm{OR}, 4.123 ; 95 \% \mathrm{Cl}, 1.834$ to $9.268 ; P=0.001)$, but not to stroke severity $(P=0.272)$. DOAC exposure had a higher explanatory value for stroke severity than concentrations at event.

Conclusions Low DOAC exposure is strongly associated to ischemic stroke and its severity. By monitoring DOAC plasma concentrations, patients prone to ischemic stroke might be identified.

Keywords Anticoagulants; Plasma; Tandem mass spectrometry; Ischemic stroke; Ischemic attack, transient

\section{Introduction}

Increasing numbers of patients exposed to direct oral anticoagulants (DOAC) are admitted to emergency departments with ischemic stroke and transient ischemic attack (TIA).$^{1-4}$ Assessing the coagulation status and DOAC plasma concentrations at
Correspondence: Timolaos Rizos Department of Neurology, University Heidelberg, Im Neuenheimer Feld 400, 69120 Heidelberg, Germany Tel: +49-6221-56-7504

Fax: +49-6221-56-5654 E-mail: timolaos.rizos@med.uniheidelberg.de https://orcid.org/0000-0002-7250-4668

Received: December 13, 2020

Revised: July 17, 2021

Accepted: September 7, 2021

*These authors contributed equally to the manuscript as first author. 
current knowledge on DOAC plasma concentrations of patients in the acute phase of stroke is still limited, but available evidence suggests high exposure variability. ${ }^{2}$ As an example, DOAC admission concentrations in the multicenter Registry of Acute Stroke Under New Oral Anticoagulants (RASUNOA) registry were below expected trough concentrations in 25\% of patients. ${ }^{2}$ Similar findings were observed in a single-center registry, which observed low plasma concentrations at admission in $27.7 \%$ of acute ischemic stroke patients ${ }^{5}$ and in another registry-based study, only including rivaroxaban-treated acute ischemic stroke patients, DOAC plasma concentrations were low in $66.3 \% .{ }^{6}$ However, these reports cannot be readily compared because they applied different definitions for low DOAC plasma ranges, used different calibrator assays, and did not standardize the timing of the measurements with respect to last drug intake. Moreover, DOAC-specific coagulation tests used in emergency situations (most commonly chromogenic anti-Xa assays) can considerably differ in terms of diagnostic performance when compared to ultraperformance liquid chromatography-tandem mass spectrometry (UPLC-MS/MS), which is the gold standard for accurate DOAC quantification and which is much more accurate in the low concentration range. ${ }^{?}$

Finally, although plasma concentrations at the time of hospital admission can guide treatment decisions, these measurements do not mirror DOAC exposure or the coagulation status at onset of an ischemic cerebrovascular event, in particular when hospital admission is considerably delayed. Knowledge of actual DOAC plasma concentrations at onset of an ischemic cerebrovascular event would enable evaluating and establishing a concentration-effect relationship and help deciding whether DOAC exposure of affected patients is within the target range (signifying non-response to treatment) or whether patients are underdosed or non-adherent.

In the present study, we addressed these questions by measuring DOAC plasma exposure at admission and estimating concentrations at the onset of ischemic symptoms.

\section{Methods}

\section{Patients and clinical data}

Consecutive patients aged $>18$ years, suspected to take a DOAC, and admitted to the neurological department of Heidelberg University Hospital due to symptoms of acute ischemic stroke or TIA between September 4, 2016 and June 12, 2018, were prospectively considered for inclusion into this observational study. Routine work-up for all patients encompassed a clinical examination by board-certified neurologists, brain imaging (computed tomography [CT] or magnetic resonance im- aging [MRI]), and assessment of the National Institutes of Health Stroke Scale (NIHSS) for stroke severity. Occlusions of brain-supplying vessels were diagnosed by $\mathrm{CT}$, MRI, or digital subtraction angiography. Occlusions of the distal internal carotid artery, the middle cerebral artery, the anterior cerebral artery, the posterior cerebral artery, or the basilar artery were defined as large vessel occlusion (LVO). Moreover, demographic variables, cardiovascular risk factors, time of symptom onset (if known), and time of hospital admission were recorded.

Nature and dose of DOAC and the time of the last DOAC intake were recorded. If the last intake was not reported or unknown $(n=58 / 211 ; 27.5 \%)$, it was assumed that the DOAC was taken regularly and that the last ingestion occurred at 8:00 AM (once a day and twice a day regimens) and 8:00 PM (twice a day schedules). Physicians' adherence to approved doses as recommended in the corresponding product characteristics (SmPCs) by the European Medicines Agency was evaluated by comparing the actual prescription scheme with the prescribing information of the respective DOAC in each patient. The degree of disability before stroke was assessed by the premorbid modified Rankin Scale (mRS). All patients with proven ischemic stroke or TIA, current DOAC prescription, and at least one immediate blood sampling at admission were considered for inclusion. Functional outcome after 3 months was assessed by the $\mathrm{mRS}$ during a standardized telephone interview.

Laboratory data and DOAC plasma concentrations As part of our standard of care, immediately after admission, standardized routine laboratory testing was performed. This included a full blood count, glucose, electrolytes, urea, creatinine, prothrombin time, activated partial thromboplastin time, international normalized ratio (INR), and DOAC plasma concentrations. DOAC plasma concentrations were measured from plasma samples drawn at admission $\left(t_{1}\right)$ and 6 hours later $\left(t_{2}\right)$ by UPLC-MS/MS (lower limit of quantification [LLOO] of $1 \mathrm{ng} / \mathrm{mL}$ ), developed and validated according to U.S. Food and Drug Administration and European Medicines Agency guidelines for bioanalytical method validation. ${ }^{8}$ DOAC exposure in the dosing interval and DOAC concentration at the onset of the ischemic event were derived from population pharmacokinetic analyses, based on established models for apixaban, ${ }_{1}^{9}$ dabigatran, ${ }^{10}$ edoxaban, ${ }_{1}^{11}$ and rivaroxaban. ${ }^{12}$ Individual pharmacokinetic parameters were obtained as empirical Bayes estimates (conditional mode) from the respective model applied to each patient together with complete profiles (data points every 2 hours) of 50 simulated individuals with identical covariates as the respective patient. Of note, we used a simplified covariate-free adaptation of the complex edoxaban model ${ }^{11}$ and generally set 
missing body weight measurements to the median value of the literature model in nine patients. For the simulated 50 virtual individuals serving as a reference, we assumed that steadystate was reached on the 5th treatment day.

Estimation of individual pharmacokinetic parameters of our patients enabled us to estimate individual concentration-time profiles (for an example, see Figure 1). Upon visual inspection of the profiles, we had to manually exclude 25 patients whose sparse data points did not yield clinically plausible profiles (Figure 2). Reasons for exclusion included (1) measurements or predicted profiles far beyond the 95\% confidence range that were to expect from regular intake at steady-state $(n=11) ;(2)$ extreme profiles that were not supported by any measurement within the regular dosing interval $(n=15)$; and (3) implausible measurement pairs (e.g., second measurement with higher value than first measurement, $n=6$; please note: more than one reason was present in single patients). Based on the remaining 192 informative profiles, we calculated the area under the curve (AUC) to describe exposures with the respective DOAC and estimate DOAC concentration at onset (if the time of the event was known).

As a measure of internal validity, we checked the agreement between model-based extrapolated concentrations and non-parametric extrapolations in a sample of patients with more than one measurement. In order to estimate individual elimination rate constants $(\lambda)$, two DOAC UPLC-MS/MS mea-

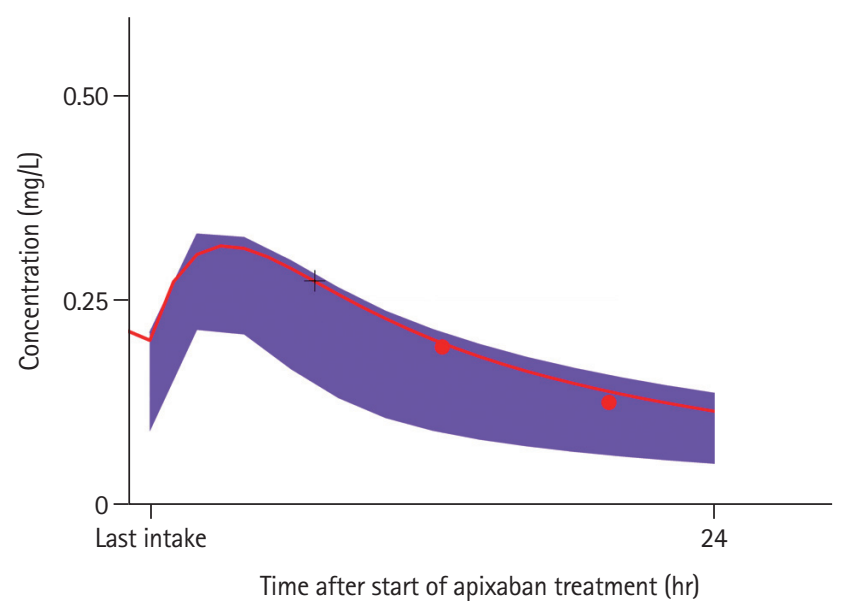

Figure 1. Model-based concentration-time profile of an exemplary patient treated with apixaban (red line). Shaded areas (purple) visualize the typical range of 95\% virtual patients as predicted from the underlying population pharmacokinetic model for apixaban while accounting for available covariates of the particular patient or assuming median values. ${ }^{9}$ Red dots represent the actual measurements in the particular patient and the red line shows the a posteriori estimates of the individual concentration-time profile based on individual pharmacokinetic parameters of the particular patient. The concentration at the time of event (+black cross) was directly derived from the profile. surements had to be available that were collected $\geq 6$ hours apart within the same dosing interval, of which the first had to be drawn not earlier than 2 hours after the last drug intake, i.e., after expected peak concentrations. The slope of the line connecting the logarithms of the two measured concentrations over time was defined as $\lambda\left[\lambda=\left(\log C_{1}-\log C_{2}\right) /\left(t_{2}-t_{1}\right)\right]$, where $C_{1}$ is the concentration in the first-drawn admission sample, $C_{2}$ the concentration in the sample collected $\geq 6$ hours after $\mathrm{C}_{1}$ within the same elimination phase, and $t_{2}-t_{1}$ the numeric interval between the corresponding concentrations.

This slope $(\lambda)$ was used to back-extrapolate concentrations $\left(C_{e}\right)$ expected at the time $\left(t_{e}\right)$ of the ischemic event $\left[\log C_{e}=\lambda\right.$ $\left.\left(t_{e}-t_{1}\right)+\log C_{1}\right]$, provided that symptom onset occurred after drug absorption (i.e., $>2$ hours after the last drug intake). In 19 patients all measurements were below the analytical LLOO; these values were set to zero and the patients were considered non-adherent.

The responsible independent Ethics Committee of the Medi-

353 Patients admitted with assumed DOAC use and suspected ischemic stroke or TIA

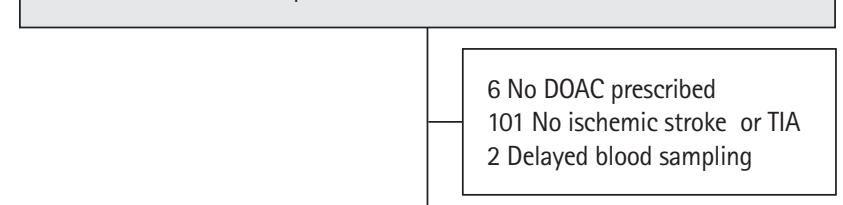

244 Patients with ischemic stroke or TIA and DOAC prescription and

blood sampling on admission for plasma DOAC concentrations (90 apixaban, 21 edoxaban, 106 rivaroxaban, and 27 dabigatran)

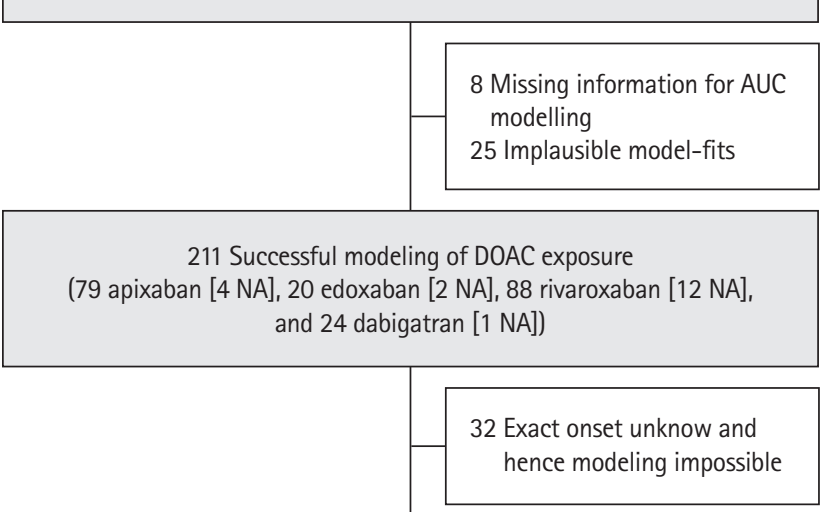

179 Successful model-based prediction of DOAC concentration at onset of ischemic stroke/TIA

(67 apixaban [4 NA], 16 edoxaban [2 NA], 78 rivaroxaban [12 NA], and 18 dabigatran [1 NA])

Figure 2. Selection of the study population. DOAC, direct oral anticoagulant; TIA, transient ischemic attack; AUC, area under the curve; NA, non-adherence. 
cal Faculty of Heidelberg University approved this study, written informed consent was obtained from patients or their legal representatives.

\section{Statistical analysis}

To facilitate standardized comparisons across the four DOACs, we calculated fold changes from dividing our estimated values by the mean concentration and AUC at steady-state extracted from external reference populations (for apixaban, ${ }^{13}$ dabiga$\operatorname{tran}_{1}{ }^{14}$ edoxaban, ${ }^{15}$ and rivaroxaban ${ }^{16}$ ). Considering measurements set to zero in non-adherent patients, the Yeo-Johnson transformation yielded power-transformed values following a normal distribution around the center peak of $0.5 .^{17}$ Thus, normalized fold changes above this normalized threshold indicated relatively higher concentrations or exposure than expected from the external reference (henceforth denoted as groups with relatively high, or vice versa low, relative DOAC AUCs or concentrations).

Standard statistical methods were applied for univariate comparisons. Multivariate logistic and linear regression was performed to explore factors explaining differences between patients with TIA and ischemic stroke, stroke severity (NIHSS), the occurrence of LVO in ischemic stroke patients, and the severity of clinical outcome (mRS) after 3 months (dichotomized at the level of 2).

To determine whether overall exposure (AUC) or the estimated concentration at the time of the event had a higher explanatory value to predict the nature of events (ischemic stroke or TIA) or stroke severity (NIHSS), we compared subpopulations for which both measures were available. Therefore, separate models were fitted including either normalized AUC or normalized concentration values as independent variables (in addition to clinical covariates for confounding adjustment). A formal model comparison of these non-nested models was based on an appropriate likelihood ratio test assessing the working hypothesis that the AUC model fits better than the respective concentration model. ${ }^{18}$

All tests were two-sided and a $P$-value of $\leq 0.05$ was considered significant. Data were analysed using the SPSS version 26.0 (IBM Co., Armonk, NY, USA), the R software/environment version 3.6.1 (R Foundation for Statistical Computing, Vienna, Austria), Monolix version 2019R2 (LIXOFT, Antony, France), and GraphPad Prism version 8.4.2 (GraphPad, La Jolla, CA, USA).

\section{Results}

\section{Selection and characteristics of patients}

The selection of the study population is illustrated in Figure 2.
The median age of the 211 patients of our primary analysis set with evaluable DOAC exposure was 80 years (interquartile range [IQR], 75 to 86), 50.7\% were female (Supplementary Table 1). Ischemic stroke was present in 74.4\%, TIA in 25.6\%. Etiology of ischemic stroke according to Trial of Org 10172 in Acute Stroke Treatment (TOAST) was cardioembolic in 79.0\% (Supplementary Table 1) and in 33.6\% LVO was observed. Most patients were either taking rivaroxaban $(n=88 ; 41.7 \%)$ or apixaban $(n=79 ; 37.4 \%)$; dabigatran was used by $24(11.4 \%)$ and edoxaban by 20 (9.5\%) (Supplementary Table 1). Expectedly, the predominant reason for oral anticoagulation was atrial fibrillation (AF; 91.0\%) and the prevalence of cardiovascular risk factors was high, resulting in a median $\mathrm{CHA}_{2} \mathrm{DS}_{2}-\mathrm{VASc}$ Score prior to the actual event of $5(I 0 R, 4$ to 6$)$.

\section{DOAC plasma concentrations at admission and DOAC exposure}

The median time between reported last drug administration and admission was 582 minutes (IQR, 282 to 891). DOAC concentrations at admission for individual DOACs are listed in Supplementary Table 1. The ratios of modeled exposure of individual patients and published average AUC values as a measure of individual DOAC exposure are presented in Figure 3 (residuals of underlying pharmacokinetic models are provided in Supplementary Figure 1). Non-adherence (UPLC-MS/

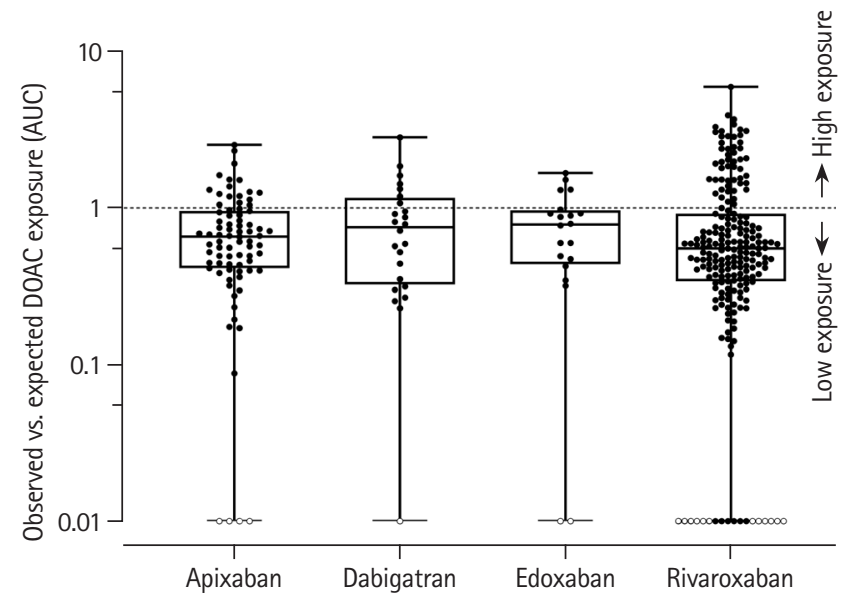

Figure 3. Box plots of the ratio of modeled area under the curve (AUC) and published figures corresponding to the respective doses with superimposed individual AUC values of all included patients. The broken line indicates the threshold between relatively higher and lower direct oral anticoagulant (DOAC) exposure than the published expected average. Each boxplot contains the median (horizontal line in the box), the upper quartile (75th percentile, top of box), the lower quartile (25th percentile, bottom of box). The whiskers plot the minimal and maximal DOAC exposure. Solid circles: Dot plots of categorized individual AUC results of all included patients (lower limit of quantification for ultraperformance liquid chromatography-tandem mass spectrometry $1 \mathrm{ng} / \mathrm{mL}$ ). Open circles: non-adherent patients (concentration $<1 \mathrm{ng} / \mathrm{mL} ; \mathrm{n}=19$ ). 
MS measurements below LLOO) was observed in 19 patients (9\%).

Lower relative DOAC exposure (AUC) than expected was observed in almost two-thirds (63.0\%) of our patients. Clinical and DOAC-specific variables in patients with relatively lower and higher DOAC exposure are given in Supplementary Table 2 as are the results of univariate correlation analyses.
Multivariate logistic regression revealed a substantially higher risk for ischemic stroke when DOAC exposure was low (odds ratio [OR], 2.411; 95\% confidence interval [Cl], 1.254 to 4.638; $P=0.008$ ) (Table 1). Adjusted for sex, age, and creatinine, low DOAC exposure was associated with physicians' non-adherence (underdosage) to SmPCs (OR, 2.125; 95\% Cl, 1.039 to 4.560; $P=0.044$ ) (Supplementary Table 3) and, in these ischemic stroke

Table 1. Multivariate logistic regression between ischemic stroke and TIA patients in all included patients and in all patients with modeled DOAC concentration at the event

\begin{tabular}{|c|c|c|c|c|c|c|}
\hline \multirow{3}{*}{ Variable } & \multicolumn{6}{|c|}{ Ischemic stroke vs. TIA } \\
\hline & \multicolumn{3}{|c|}{$\begin{array}{l}\text { All included patients } \\
\qquad(n=211)\end{array}$} & \multicolumn{3}{|c|}{$\begin{array}{l}\text { Patients with extrapolated DOAC concentration } \\
\text { at the event }(n=179)\end{array}$} \\
\hline & OR & $95 \% \mathrm{Cl}$ & $P$ & OR & $95 \% \mathrm{Cl}$ & $P$ \\
\hline Low DOAC exposure* & 2.411 & $1.254-4.638$ & 0.008 & - & - & - \\
\hline Low DOAC concentration at event ${ }^{*}$ & $-^{+}$ & - & - & 4.123 & $1.834-9.268$ & 0.001 \\
\hline Female sex & 0.610 & $0.294-1.270$ & 0.187 & 0.528 & $0.244-1.145$ & 0.106 \\
\hline Age & 0.961 & $0.917-1.008$ & 0.100 & 0.983 & $0.935-1.034$ & 0.506 \\
\hline Hypertension & 1.132 & $0.365-3.516$ & 0.830 & 0.722 & $0.204-2.555$ & 0.614 \\
\hline Diabetes mellitus & 0.487 & $0.235-1.008$ & 0.053 & 0.340 & $0.149-0.774$ & 0.010 \\
\hline Hypercholesterolemia & 0.657 & $0.320-1.347$ & 0.251 & 0.726 & $0.324-1.624$ & 0.435 \\
\hline Previous stroke/TIA & 1.066 & $0.531-2.142$ & 0.857 & 0.956 & $0.440-2.078$ & 0.956 \\
\hline Congestive heart failure & 1.428 & $0.576-3.540$ & 0.442 & 1.436 & $0.534-3.857$ & 0.473 \\
\hline Vascular disease & 0.940 & $0.445-1.989$ & 0.872 & 1.047 & $0.460-2.385$ & 0.912 \\
\hline Atrial fibrillation & 0.880 & $0.254-3.049$ & 0.076 & 0.907 & $0.229-3.600$ & 0.890 \\
\hline
\end{tabular}

TIA, transient ischemic attack; DOAC, direct oral anticoagulant; $\mathrm{OR}$, odds ratio; $\mathrm{Cl}$, confidence interval.

${ }^{*}$ Derived from area under the curve (AUC) ratios normalized to reference populations; ${ }^{+}$No published data available for comparison.

Table 2. Multivariate linear regression of stroke severity (NIHSS) in all included ischemic stroke patients and in all ischemic stroke patients with modeled DOAC concentration at the event

\begin{tabular}{|c|c|c|c|c|c|c|}
\hline \multirow{3}{*}{ Variable } & \multicolumn{6}{|c|}{ NIHSS } \\
\hline & \multicolumn{3}{|c|}{$\begin{array}{l}\text { All included ischemic stroke patients } \\
\qquad(n=157)\end{array}$} & \multicolumn{3}{|c|}{$\begin{array}{l}\text { Ischemic stroke patients with extrapolated DOAC concentration } \\
\qquad \text { at the event }(n=131)\end{array}$} \\
\hline & Slope & $95 \% \mathrm{Cl}$ & $P$ & Slope & $95 \% \mathrm{Cl}$ & $P$ \\
\hline Low DOAC exposure* & 3.161 & 0.741 to 5.581 & 0.011 & - & - & - \\
\hline Low DOAC concentration at event* & $-^{+}$ & - & - & 1.570 & -1.320 to 4.334 & 0.293 \\
\hline Female sex & -2.708 & -5.125 to -0.291 & 0.028 & -2.559 & -5.398 to 0.281 & 0.077 \\
\hline Age & 0.076 & -0.053 to 0.205 & 0.246 & 0.099 & -0.060 to 0.257 & 0.220 \\
\hline Hypertension & 0.103 & -3.717 to 3.924 & 0.957 & 0.379 & -3.875 to 4.633 & 0.860 \\
\hline Diabetes mellitus & 0.380 & -2.312 to 3.072 & 0.781 & 0.154 & -3.214 to 3.522 & 0.928 \\
\hline Hypercholesterolemia & -1.629 & -4.039 to 0.780 & 0.183 & -1.454 & -4.318 to 1.409 & 0.317 \\
\hline Previous stroke/TIA & 1.737 & -0.769 to 4.243 & 0.173 & 1.661 & -1.322 to 4.644 & 0.272 \\
\hline Congestive heart failure & 1.001 & -1.924 to 3.927 & 0.500 & 1.119 & -2.383 to 4.622 & 0.528 \\
\hline Vascular disease & 1.212 & -1.292 to 3.717 & 0.340 & 1.354 & -1.648 to 4.356 & 0.374 \\
\hline Large vessel occlusion & 7.773 & 5.449 to 10.098 & $<0.001$ & 7.597 & 4.796 to 10.397 & $<0.001$ \\
\hline Atrial fibrillation & 2.285 & -1.687 to 6.257 & 0.257 & 1.936 & -2.977 to 6.850 & 0.437 \\
\hline
\end{tabular}

NIHSS, National Institutes of Health Stroke Scale; DOAC, direct oral anticoagulant; $\mathrm{Cl}$, confidence interval; $\mathrm{TIA}$, transient ischemic attack.

${ }^{*}$ Derived from ratios normalized to reference populations; ${ }^{+}$No published data available for comparison. 
patients, low DOAC exposure was associated with greater stroke severity (NIHSS; $P=0.011$; multivariate linear regression) (Table 2), but not with the presence of $\mathrm{LVO}(\mathrm{OR}, 1.360 ; 95 \% \mathrm{Cl}$, 0.660 to $2.803 ; P=0.404$ ) (Supplementary Table 4).

\section{Estimated DOAC concentrations at the time of event}

Information on the specific time of ischemic stroke or TIA was available in 179/211 patients thus allowing to extrapolate DOAC concentration at the time of the event (Figure 2). The median time between last drug intake and event was 480 minutes (IOR, 210 to 690) and neither differed between individual substances $\left(P_{\mathrm{ANovA}}=0.173\right)$ nor between substances with once (rivaroxaban and edoxaban) or twice daily use (apixaban and dabigatran, $P=0.221$ ). Moreover, non-parametric comparison of the intervals between the time of the last drug intake and time of the event revealed no difference between TIA and ischemic stroke patients $\left(P_{\text {Mann-Whitney-U test }}=0.832\right)$.

Univariate comparisons between patients with relatively lower and higher DOAC concentrations are provided in Supplementary Table 5. Multivariate logistic regression analysis revealed that patient with low relative onset concentrations were also more likely to suffer ischemic stroke than TIA (OR, 4.123; $95 \% \mathrm{Cl}, 1.834$ to 9.268; $P=0.001$ ) (Table 1), but no association with stroke severity (NIHSS) was present $(P=0.222)$ (Table 2). In ischemic stroke, lower DOAC concentrations at event onset were not associated with the presence of LVO $(O R, 0.619 ; 95 \% \mathrm{Cl}, 0.287$ to $1.335 ; P=0.222$ ) (Supplementary Table 4).

\section{Sensitivity analyses and substance-specific influences}

Sensitivity analyses with alternating event definitions revealed robust results for the influence of DOAC exposure and DOAC plasma concentration at the time of the event on the risk of ischemic stroke also when data were restricted to patients with AF or patients with cardioembolic ischemic strokes (Supplementary Figure 2). No substance-specific modulation of the overall DOAC effect of exposure (AUC) or event concentration was present (Supplementary Figure 3). Hence, substance-specific influences did not appear to be present in our cohort.

\section{Significance of DOAC exposure and DOAC concentration at event}

In ischemic stroke patients, DOAC exposure (AUC) better predicted the stroke severity than estimated DOAC concentration at the event $(P=0.049)$. However, AUC did not better explain the nature of observed ischemic events than estimated DOAC concentration $(P=0.939)$.

\section{Functional outcome}

Overall, in 199 patients of our cohort (94.3\%), follow-up information after 3 months was available. In these patients, median functional outcome (mRS) was 3 (1 to 5) (Supplementary Table 1). Of all included patients with ischemic stroke $(n=157)$, follow-up information was available in 149 patients (94.9\%). An unfavorable outcome (mRS 3-6) was observed in 92 of them (61.7\%). Differences between ischemic stroke patients with favorable (mRS 0-2) and unfavorable (mRS 3-6) outcome are presented in Supplementary Table 6. In univariate analyses, neither DOAC exposure nor estimated concentration at the time of stroke were associated with the 3-month outcome (Supplementary Table 6). Multivariate logistic regression revealed that only stroke severity $(\mathrm{OR}, 1.174 ; 95 \% \mathrm{Cl}, 1.079$ to $1.278 ; P<0.001)$ and the premorbid functional status (OR, $2.881 ; 95 \% \mathrm{Cl}, 1.720$ to $4.828 ; P<0.001)$ were independently associated with an unfavorable outcome after 3 months (Supplementary Table 7).

\section{Discussion}

The main findings of our study are that (1) a large proportion of patients hospitalized with acute ischemic cerebrovascular events had lower than expected DOAC exposure; (2) these patients were more likely to have a stroke than a TIA and their strokes were more severe; and (3) low DOAC exposure was more likely when the prescribed dosage regimens contradicted approved standards. Finally (4) DOAC exposure had a higher explanatory value for stroke severity than single concentrations at the time of the event.

In contrast to vitamin $\mathrm{K}$ antagonists (VKAs), the anticoagulatory effect of all DOACs is rapid and clearly concentration-dependent, ${ }^{19,20}$ suggesting that current plasma concentrations might reflect efficacy. In fact, concentration monitoring in pivotal DOAC trials revealed that important clinical endpoints, including ischemic stroke, correlated with DOAC trough concentrations. ${ }^{21,22}$ Although, ischemic stroke in patients taking DOACs has become an important and common scenario in clinical practice, data on actual DOAC plasma concentrations in the hyperacute phase of stroke are still limited, not least because these events typically occur outside direct medical care. In particular, it is unknown whether DOAC plasma concentrations reflect clinical endpoints as well as they mirror the inhibition of coagulation factors.

Because of the importance of supporting acute treatment 
decisions, studies in DOAC-pretreated patients with acute cerebrovascular events have so far used the results of (faster) non-specific or specific coagulation tests as surrogates for DOAC activity at the time of hospital admission, which occurs often hours after event onset. However, such single activity testing of coagulation parameters represents an approximate snap-shot of the actual DOAC plasma concentration only, the quality of anticoagulation over time cannot be assessed and it gives no information on DOAC concentrations at the event time. To close this gap, we meticulously collected information on dose and time of individual drug intake, modeled individual concentration-time profiles, and correlated these data with the reported occurrence of stroke symptoms. This approach is independent of time of admission and considers the specifics of individual dosing regimens and drug intake. To the best of our knowledge, this is the first study designed to evaluate the significance of DOAC plasma concentrations at the event for the occurrence of TIA, ischemic strokes, and their severity.

Irrespective of the prescribed DOAC, exposure of our patients was lower than expected and in a substantial proportion of patients this was a result of physicians' non-adherence to guidelines (underdosing: 24.2\%) or non-adherence of patients (9\%). Poor guideline adherence with a trend to lower doses has been reported repeatedly and is associated with less favorable outcomes. ${ }^{23}$ Similarly, also poor patient adherence and persistence is alarmingly frequent and associated with increased frequencies of thromboembolic events and death. ${ }^{24}$ In accordance with the known relationship between DOAC dose and efficacy, our study revealed that patients with DOAC plasma exposure below the population mean were 2.4 times more likely to have a stroke than a TIA and their strokes were more severe. This difference was maintained when comparing the DOAC concentrations at the time of the ischemic event but the latter did not correlate with stroke severity. Because no study evaluated DOAC plasma concentrations at the time of ischemic stroke before, comparison of our results to former reports is not possible. In descriptive analyses, a single-center registry study assessing associations between specific coagulation tests and clinical and imaging characteristics reported lower functional plasma levels at hospital admission to be associated with stroke severity, higher risk of persisting neurological deficits, and cerebral infarction on brain imaging. ${ }^{5}$ Furthermore, in a multivariate model, low results of such coagulation tests were observed to be an independent predictor of LVO. ${ }^{5}$ However, differences between TIA and ischemic stroke patients were not analysed and time-intervals between last DOAC administration and laboratory assessments was not reported. ${ }^{5}$ By considering DOAC dosing schemes prior to ischemic stroke, another analysis of this registry revealed that only one in three patients with ischemic stroke followed appropriately dosed DOAC regimes and underdosing was associated to greater stroke severity and worse functional outcome after 3 months. ${ }^{25}$ However, only patients using coagulation factor Xa inhibitors were included and no DOAC plasma concentrations were measured at admission thus leaving open whether exposure was indeed low. A further retrospective evaluation of patients with recurrent ischemic stroke at a tertiary stroke center reported that missed DOAC use for $\geq 48$ hours or DOAC dosing below current recommendations were associated with $\mathrm{LVO}^{26}$ However again, no information on DOAC plasma concentrations was included. ${ }^{26}$

Our study enabled to determine whether DOAC exposure over time (AUC) or the concentration at event onset better predicted ischemic stroke or its severity and found that AUC was superior to explain stroke severity than DOAC concentration at the time of the event. Our findings therefore suggest that lower DOAC exposure (and not the concentration at stroke onset) is more relevant for treatment efficacy. These results are in accordance to other reports, suggesting that AUC values might more closely reflect actual drug action than either peak $^{27,28}$ or trough DOAC concentrations; ${ }_{i}^{29}$ however, this appears not to be true for all DOACs. ${ }^{29}$

When transferring the broad knowledge on treatment with VKA to DOAC patients, our observation that stroke severity was better predicted by DOAC exposure than by plasma concentration at the event is plausible. Exposure to VKA can be expressed by INR values and it is well known that INR values of $\geq 2.0$ reduce the frequency of ischemic stroke and its severity as well as the risk of death from stroke in patients with $\mathrm{AF}^{30}$ Moreover, the proportion of treatment time outside the therapeutic range has been clearly associated with adverse outcomes, including ischemic stroke. ${ }^{31,32}$ Furthermore, admission INR values are inversely correlated with infarct volume on diffusion-weighted MRI imaging ${ }^{33}$ and the intensity of anticoagulation with VKAs in cardioembolic ischemic stroke is inversely associated with the severity of neurological deficits and clinical outcome. ${ }^{34}$ Such observations are the foundation for the generally known and established recommendation to thoroughly monitor INR values in VKA patients to gain optimal prevention for thromboembolic events by achieving adequate drug exposure.

Taken together, our findings have important clinical implications for the future management of patients using DOACs. By now, recommendations to perform regular controls of plasma concentrations in DOACs are absent. In contrast, our data suggest that monitoring these patients by thorough control of dosing schemes and long-term drug exposure might help iden- 
tifying patients with inadequately low exposure and subsequent dose adaptions could considerably improve stroke prevention. Whether this strategy will help improving outcomes will now have to be tested in a prospective clinical trial.

An obvious strength of the present study is the prospective inclusion of a large number of anticoagulated acute ischemic stroke and TIA patients, irrespective of a prespecified DOAC treatment. Moreover, external standardization of DOAC plasma concentrations provided sound knowledge on associations between DOAC plasma concentrations and ischemic cerebrovascular events. However, modeled exposure in our study is based on the existent literature and limited to the last hours before stroke. Longitudinal exposure information was not available, the numbers of patients for single DOACs are limited and the single-center approach might restrict generalizing our results. It could be speculated that assuming a regular drug use in patients in whom the last drug intake was not reported or unknown may have generated bias. However, excluding these patients yielded even higher risks for stroke occurrence due to low DOAC plasma exposure (OR, 2.99, data not shown). This indicates that the main approach of approximating drug intake times in those patients can be considered as rather conservative as main results appeared to be biased towards the null, if at all. Due to the observational design, we did not perform brain imaging in a predefined structured manner and therefore cannot adequately report stroke volumes. Moreover, we did not consider details of recanalization therapies or changes in renal function when determining the functional outcome. Longitudinal information on exposure was not available, the number of patients with individual DOACs was small, as was the number of 1-2 observations per patient available for extrapolation of individual pharmacokinetics. The lack of a control group and of patients with intracerebral hemorrhages is a further limitation.

\section{Conclusions}

Our data reveal that low DOAC exposure is strongly associated to ischemic stroke and its severity. In consequence, monitoring plasma concentrations in DOAC patients on a regular basis might identify patients prone to ischemic stroke and subsequent dose adaptions could considerably improve preventing ischemic cerebrovascular events by achieving adequate DOAC exposure. Monitoring these patients longitudinally would also enable to examine associations between the impact of duration of suboptimal anticoagulation on the occurrence of cerebrovascular events. This should now be assessed in an adequately powered prospective trial.

\section{Supplementary materials}

Supplementary materials related to this article can be found online at https://doi.org/10.5853/jos.2020.04952.

\section{Disclosure}

Timolaos Rizos received consulting honoraria, speakers' honoraria and travel support from Bristol-Myers Squibb/Pfizer, Boehringer Ingelheim, Bayer HealthCare, Portola Pharmaceuticals and Daiichi Sankyo, outside of the present work; Jan Purrucker received consulting honoraria and travel support from Abbott, Akcea, Boehringer Ingelheim, Daiichi Sankyo and Pfizer, outside of the present work; David Czock received honoraria and travel support from Biogen $\mathrm{GmbH}$, Chiesi $\mathrm{GmbH}$ and Daiichi Sankyo, outside of the present work; Peter A. Ringleb and Walter E. Haefeli received honoraria from Bayer, Boehringer Ingelheim, Daiichi Sankyo and Pfizer, outside of the present work.

Andreas D. Meid, Chris Dumschat, Andrea Huppertz, Kathrin I. Foerster, Jürgen Burhenne, and Ekkehart Jenetzky report no disclosures.

\section{Acknowledgments}

The work of Andreas D. Meid was supported by a grant from the Medical Faculty of Heidelberg University (Physician Scientist program).

\section{References}

1. Purrucker JC, Steiner T. Management of acute stroke in patients on oral anticoagulants. Curr Opin Neurol 2017;30:1-7.

2. Purrucker JC, Haas K, Rizos T, Khan S, Poli S, Kraft P, et al. Coagulation testing in acute ischemic stroke patients taking non-vitamin k antagonist oral anticoagulants. Stroke 2017; 48:152-158.

3. Seiffge DJ, Traenka C, Polymeris A, Hert L, Fisch U, Peters N, et al. Feasibility of rapid measurement of rivaroxaban plasma levels in patients with acute stroke. J Thromb Thrombolysis 2017;43:112-116.

4. Volbers B, Köhrmann $M$, Kallmünzer B, Kurka N, Breuer $L$, Ringwald J, et al. Dabigatran plasma levels in acute cerebrovascular events. J Stroke Cerebrovasc Dis 2016;25:877-882.

5. Macha K, Marsch A, Siedler G, Breuer L, Strasser EF, Engelhorn $T$, et al. Cerebral ischemia in patients on direct oral anticoagulants. Stroke 2019;50:873-879.

6. Seiffge DJ, Kägi G, Michel P, Fischer U, Béjot Y, Wegener $S$, et 
al. Rivaroxaban plasma levels in acute ischemic stroke and intracerebral hemorrhage. Ann Neurol 2018;83:451-459.

7. Gosselin RC, Adcock DM, Bates SM, Douxfils J, Favaloro EJ, Gouin-Thibault I, et al. International Council for Standardization in Haematology (ICSH) recommendations for laboratory measurement of direct oral anticoagulants. Thromb Haemost 2018;118:437-450.

8. Foerster KI, Huppertz A, Müller OJ, Rizos T, Tilemann L, Haefeli $W E$, et al. Simultaneous quantification of direct oral anticoagulants currently used in anticoagulation therapy. $J$ Pharm Biomed Anal 2018;148:238-244.

9. Byon W, Sweeney K, Frost C, Boyd RA. Population pharmacokinetics, pharmacodynamics, and exploratory exposure-response analyses of apixaban in subjects treated for venous thromboembolism. CPT Pharmacometrics Syst Pharmacol 2017;6:340-349.

10. Liesenfeld KH, Lehr T, Dansirikul C, Reilly PA, Connolly SJ, Ezekowitz MD, et al. Population pharmacokinetic analysis of the oral thrombin inhibitor dabigatran etexilate in patients with non-valvular atrial fibrillation from the RE-LY trial. $J$ Thromb Haemost 2011;9:2168-2175.

11. Krekels EH, Niebecker R, Karlsson M0, Miller R, Shimizu T, Karlsson KE, et al. Population pharmacokinetics of edoxaban in patients with non-valvular atrial fibrillation in the ENGAGE AF-TIMI 48 study, a phase III clinical trial. Clin Pharmacokinet 2016;55:1079-1090.

12. Girgis IG, Patel MR, Peters GR, Moore KT, Mahaffey KW, Nessel $\mathrm{CC}$, et al. Population pharmacokinetics and pharmacodynamics of rivaroxaban in patients with non-valvular atrial fibrillation: results from ROCKET AF. J Clin Pharmacol 2014; 54:917-927.

13. Cirincione B, Kowalski K, Nielsen J, Roy A, Thanneer N, Byon $W$, et al. Population pharmacokinetics of apixaban in subjects with nonvalvular atrial fibrillation. CPT Pharmacometrics Syst Pharmacol 2018;7:728-738.

14. Stangier J. Clinical pharmacokinetics and pharmacodynamics of the oral direct thrombin inhibitor dabigatran etexilate. Clin Pharmacokinet 2008;47:285-295.

15. Yin 00, Tetsuya K, Miller R. Edoxaban population pharmacokinetics and exposure-response analysis in patients with non-valvular atrial fibrillation. Eur J Clin Pharmacol 2014;70: 1339-1351.

16. Assessment report Xarelto VHF. European Medicines Agency. https://www.ema.europa.eu/en/documents/variation-report/ xarelto-h-c-944-ii-0012-epar-assessment-report-variation en.pdf. 2012. Accessed November 24, 2021.

17. Yeo IK, Johnson RA. A new family of power transformations to improve normality or symmetry. Biometrika 2000;87:954-
959.

18. Vuong $\mathrm{QH}$. Likelihood ratio tests for model selection and non-nested hypotheses. Econometrica 1989;57:307-333.

19. Wang $X$, Tirucherai G, Marbury TC, Wang J, Chang M, Zhang $D$, et al. Pharmacokinetics, pharmacodynamics, and safety of apixaban in subjects with end-stage renal disease on hemodialysis. J Clin Pharmacol 2016;56:628-636.

20. Kubitza D, Becka M, Wensing G, Voith B, Zuehlsdorf M. Safety, pharmacodynamics, and pharmacokinetics of BAY 597939-an oral, direct Factor Xa inhibitor: after multiple dosing in healthy male subjects. Eur J Clin Pharmacol 2005;61: 873-880.

21. Reilly PA, Lehr T, Haertter S, Connolly SJ, Yusuf S, Eikelboom $J W$, et al. The effect of dabigatran plasma concentrations and patient characteristics on the frequency of ischemic stroke and major bleeding in atrial fibrillation patients: the RE-LY Trial (Randomized Evaluation of Long-Term Anticoagulation Therapy). J Am Coll Cardiol 2014;63:321-328.

22. Ruff CT, Giugliano RP, Braunwald E, Morrow DA, Murphy SA, Kuder JF, et al. Association between edoxaban dose, concentration, anti-factor Xa activity, and outcomes: an analysis of data from the randomised, double-blind ENGAGE AF-TIMI 48 trial. Lancet 2015;385:2288-2295.

23. Steinberg BA, Shrader $P$, Pieper $K$, Thomas L, Allen LA, Ansell $J$, et al. Frequency and outcomes of reduced dose non-vitamin $\mathrm{K}$ antagonist anticoagulants: results from ORBIT-AF II (The Outcomes Registry for Better Informed Treatment of Atrial Fibrillation II). J Am Heart Assoc 2018;7:e007633.

24. Borne RT, O'Donnell C, Turakhia MP, Varosy PD, Jackevicius CA, Marzec LN, et al. Adherence and outcomes to direct oral anticoagulants among patients with atrial fibrillation: findings from the veterans health administration. BMC Cardiovasc Disord 2017;17:236.

25. Stoll S, Macha K, Marsch A, Gerner ST, Siedler G, Fröhlich K, et al. Ischemic stroke and dose adjustment of oral Factor $\mathrm{Xa}$ inhibitors in patients with atrial fibrillation. J Neurol 2020; 267:2007-2012.

26. Woo HG, Chung I, Gwak DS, Kim BK, Kim BJ, Bae HJ, et al. Recurrent ischemic stroke in atrial fibrillation with non-vitamin K antagonist oral anticoagulation. J Clin Neurosci 2019; 64:127-133.

27. Herink MC, Zhuo YF, Williams CD, DeLoughery TG. Clinical management of pharmacokinetic drug interactions with direct oral anticoagulants (DOACs). Drugs 2019;79:1625-1634.

28. Leil TA, Feng Y, Zhang L, Paccaly A, Mohan P, Pfister M. Quantification of apixaban's therapeutic utility in prevention of venous thromboembolism: selection of phase III trial dose. Clin Pharmacol Ther 2010;88:375-382. 
29. Sakaguchi T, Osanai $H$, Murase $Y$, Ishii $H$, Nakashima $Y$, Asano $\mathrm{H}$, et al. Monitoring of anti-Xa activity and factors related to bleeding events: a study in Japanese patients with nonvalvular atrial fibrillation receiving rivaroxaban. J Cardiol 2017; 70:244-249.

30. Hylek EM, Go AS, Chang Y, Jensvold NG, Henault LE, Selby $\mathrm{JV}$, et al. Effect of intensity of oral anticoagulation on stroke severity and mortality in atrial fibrillation. $N$ Engl J Med 2003;349:1019-1026.

31. Gallagher AM, Setakis E, Plumb JM, Clemens A, van Staa TP. Risks of stroke and mortality associated with suboptimal anticoagulation in atrial fibrillation patients. Thromb Haemost 2011;106:968-977.

32. Connolly SJ, Pogue J, Eikelboom J, Flaker G, Commerford P,
Franzosi MG, et al. Benefit of oral anticoagulant over antiplatelet therapy in atrial fibrillation depends on the quality of international normalized ratio control achieved by centers and countries as measured by time in therapeutic range. Circulation 2008;118:2029-2037.

33. Ay $H$, Arsava EM, Gungor $L$, Greer $D$, Singhal $A B$, Furie $K L$, et al. Admission international normalized ratio and acute infarct volume in ischemic stroke. Ann Neurol 2008;64:499506.

34. Nakamura A, Ago T, Kamouchi M, Hata J, Matsuo R, Kuroda $J$, et al. Intensity of anticoagulation and clinical outcomes in acute cardioembolic stroke: the Fukuoka Stroke Registry. Stroke 2013;44:3239-3242. 
Supplementary Table 1. Demographic findings, cardiovascular risk factors, and DOAC-specific findings of all included patients $(n=211)$

\begin{tabular}{|c|c|c|c|c|c|}
\hline Variable & AUC cohort $(n=211,100 \%)$ & Apixaban $(n=79,100 \%)$ & Edoxaban $(n=20,100 \%)$ & Rivaroxaban $(n=88,100 \%)$ & Dabigatran $(n=24,100 \%)$ \\
\hline Female sex & $107(50.7)$ & $46(58.2)$ & $9(45.0)$ & $40(45.5)$ & $12(50.0)$ \\
\hline Age (yr) & $80(75-86)$ & 82 (77-88) & $78(75-81)$ & $79(73-86)$ & 78 (75-83) \\
\hline Body weight (kg) & $\begin{array}{l}75(65-85) \\
201(95.3)\end{array}$ & $\begin{array}{l}74(65-83) \\
75(94.9)\end{array}$ & $\begin{array}{l}78(70-85) \\
20(100)\end{array}$ & $\begin{array}{l}75(65-85) \\
83(94.3)\end{array}$ & $\begin{array}{l}81(64-92) \\
23(95.8)\end{array}$ \\
\hline Ischemic stroke & $157(74.4)$ & $59(74.7)$ & $17(85.0)$ & $61(69.3)$ & $20(83.3)$ \\
\hline TIA & $54(25.6)$ & $20(25.3)$ & $3(15.0)$ & $27(30.7)$ & $4(16.7)$ \\
\hline $\begin{array}{l}\text { Large vessel occlusion (ICA, MCA [1-3], } \\
\text { PCA, ACA, BA) }\end{array}$ & $71(33.6)$ & $27(34.2)$ & $6(30.0)$ & $32(36.4)$ & $6(25.0)$ \\
\hline Large-artery atherosclrosis* & $21(13.4)$ & $5(8.5)$ & $3(17.6)$ & $10(16.4)$ & $3(15.0)$ \\
\hline Cardioembolism* & $124(79.0)$ & $53(89.8)$ & $12(70.6)$ & $46(75.4)$ & $13(65.0)$ \\
\hline Small-vessel occlusion* & $2(1.3)$ & $0(0)$ & $1(5.9)$ & $1(1.6)$ & $0(0)$ \\
\hline Stroke of other determined etiology* & $0(0)$ & $0(0)$ & $0(0)$ & $0(0)$ & $0(0)$ \\
\hline Stroke of undetermined etiology ${ }^{*}$ & $10(6.4)$ & $1(1.7)$ & $1(5.9)$ & $4(6.6)$ & $4(20.0)$ \\
\hline Time of ischemic stroke/TIA (00:00-7:59) ${ }^{+}$ & $33(18.4)$ & $18(26.9)$ & $3(18.8)$ & $8(10.3)$ & $4(22.2)$ \\
\hline Time of ischemic stroke/TIA (8:00-15:59) ${ }^{+}$ & 94 (52.5) & $30(44.8)$ & $6(37.5)$ & 48 (61.5) & $10(55.6)$ \\
\hline Time of ischemic stroke/TIA (16:00-23:59) ${ }^{+}$ & $52(29.1)$ & $19(28.4)$ & $7(43.8)$ & $22(28.2)$ & $4(22.2)$ \\
\hline \multicolumn{6}{|l|}{ Functional impairment } \\
\hline $\begin{array}{l}\text { Admission NIHSS of patients with } \\
\text { ischemic stroke }\end{array}$ & $6(3-16)$ & $7(4-18)$ & $4(2-15)$ & $9(3-15)$ & $4(1-11)$ \\
\hline Premorbid modified Rankin Scale & $1(0-3)$ & $2(0-3)$ & $1(0-2)$ & $1(0-3)$ & $1(0-3)$ \\
\hline Modified Rankin Scale at 3 months & $\begin{array}{r}3(1-5) \\
199(94.3)\end{array}$ & $\begin{array}{r}3(1-6) \\
74(93.7)\end{array}$ & $\begin{array}{r}1(0-4) \\
19(95.0)\end{array}$ & $\begin{array}{r}2(0-5) \\
83(94.3)\end{array}$ & $\begin{array}{r}3(1-3) \\
23(95.8)\end{array}$ \\
\hline \multicolumn{6}{|l|}{ Comorbidities } \\
\hline Arterial hypertension & $190(90.0)$ & $70(88.6)$ & $19(95.0)$ & $78(88.6)$ & $23(95.8)$ \\
\hline Diabetes & $68(32.2)$ & $28(35.4)$ & $2(10.0)$ & $24(27.3)$ & $14(58.3)$ \\
\hline Hypercholesterolemia & $119(56.4)$ & $39(49.4)$ & $15(75.0)$ & $51(58.0)$ & $14(58.3)$ \\
\hline Previous stroke or TIA & $74(35.1)$ & $33(41.8)$ & $6(30.0)$ & $29(33.0)$ & $6(25.0)$ \\
\hline Congestive heart failure & $40(19.0)$ & $17(21.5)$ & $4(20.0)$ & $14(15.9)$ & $5(20.8)$ \\
\hline Vascular disease & $114(54.0)$ & $39(49.4)$ & $9(45.0)$ & $49(55.7)$ & $17(70.8)$ \\
\hline Atrial fibrillation & $192(91.0)$ & $73(92.4)$ & $17(85.0)$ & $80(90.9)$ & $22(91.7)$ \\
\hline Premorbid $\mathrm{CHA}_{2} \mathrm{DS}_{2}$-VASc score & $5(4-6)$ & $5(4-7)$ & $5(4-6)$ & $5(4-6)$ & $6(5-7)$ \\
\hline Creatinine at admission $(\mathrm{mg} / \mathrm{dL})$ & $0.92(0.77-1.14)$ & $0.93(0.75-1.23)$ & $0.93(0.76-1.04)$ & $0.95(0.77-1.14)$ & $0.85(0.77-1.12)$ \\
\hline eGFR $(\mathrm{mL} / \mathrm{min})^{+}$ & $\begin{array}{l}62.0(47.6-82.2) \\
167(79.1)\end{array}$ & $\begin{array}{l}56.6(43.2-78.9) \\
61(77.2)\end{array}$ & $\begin{array}{l}67.6(52.2-83.4) \\
16(80.0)\end{array}$ & $\begin{array}{l}65.4(48.2-82.6) \\
73(83.0)\end{array}$ & $\begin{array}{l}63.7(55.2-87.5) \\
17(70.8)\end{array}$ \\
\hline \multicolumn{6}{|l|}{ Pharmacotherapy } \\
\hline Additional antiplatelet therapy & $19(9.0)$ & $6(7.6)$ & $1(5.0)$ & $9(10.2)$ & $3(12.5)$ \\
\hline $\begin{array}{l}\text { Time between last DOAC intake and } \\
\text { admission (min) }\end{array}$ & $582(282-891)$ & $542(298-826)$ & $658(432-1293)$ & $610(275-955)$ & $420(205-795)$ \\
\hline $\begin{array}{l}\text { Time between DOAC intake and event } \\
(\mathrm{min})^{+}\end{array}$ & $\begin{array}{l}480(210-690) \\
179(84.8)\end{array}$ & $\begin{array}{l}450(280-630) \\
67(84.8)\end{array}$ & $\begin{array}{l}515(378-1043) \\
16(80.0)\end{array}$ & $\begin{array}{l}450(150-848) \\
78(88.6)\end{array}$ & $\begin{array}{l}495(229-668) \\
18(75.0)\end{array}$ \\
\hline $\begin{array}{l}\text { DOAC concentration }{ }^{\S} \text { at admission } \\
(\mathrm{ng} / \mathrm{mL})\end{array}$ & $110.0(42.2-220.0)$ & $123.0(59.6-210.0)$ & $38.0(11.9-103.7)$ & $127.5(26.4-291.5)$ & $83.8(47.6-200.8)$ \\
\hline Power transformed normalized AUC & $0.4399(0.2889-0.5793)$ & $0.3949(0.2916-0.4881)$ & $0.4387(0.3036-0.4903)$ & $0.5610(0.2722-0.6730)$ & $0.4284(0.2447-0.5355)$ \\
\hline $\begin{array}{l}\text { Power transformed normalized DOAC } \\
\text { concentration at event onset }^{\dagger}\end{array}$ & $\begin{array}{l}0.5577(0.2573-0.8037) \\
\quad 179(84.8)\end{array}$ & $\begin{array}{l}0.5810(0.4604-0.7924) \\
\quad 67(84.8)\end{array}$ & $\begin{array}{l}0.3204(0.823-0.6051) \\
16(80.0)\end{array}$ & $\begin{array}{l}0.5883(0.1791-0.8610) \\
\quad 78(88.6)\end{array}$ & $\begin{array}{l}0.3927(0.2394-0.5747) \\
18(75.0)\end{array}$ \\
\hline Non-adherence & $19(9.0)$ & $4(5.1)$ & $2(10.0)$ & $12(13.6)$ & $1(4.2)$ \\
\hline \multicolumn{6}{|l|}{ Prescription quality } \\
\hline DOAC adherence to SmPCs: underdosed & $51(24.2)$ & $25(31.6)$ & $2(10.0)$ & $23(26.1)$ & $1(4.2)$ \\
\hline $\begin{array}{l}\text { DOAC adherence to SmPCs: correctly } \\
\text { dosed }\end{array}$ & $153(72.5)$ & $53(67.1)$ & $18(90.0)$ & $60(68.2)$ & $22(91.7)$ \\
\hline DOAC adherence to SmPCs: overdosed & $7(3.3)$ & $1(1.3)$ & $0(0)$ & $5(5.7)$ & $1(4.2)$ \\
\hline
\end{tabular}

Values are presented as number (\%) or median (interquartile range).

DOAC, direct oral anticoagulant; AUC, area under the curve; TIA, transient ischemic attack; ICA, internal carotid artery; MCA (1-3), middle cerebral artery (segments 1-3); PCA, posterior cerebral artery; ACA, anterior cerebral artery; BA, basilar artery; NIHSS, National Institutes of Health Stroke Scale; eGFR, estimated glomerular filtration rate; $\mathrm{SmPC}$, recommended doses from summaries of product characteristic.

${ }^{*}$ According to Trial of Org 10172 in Acute Stroke Treatment (TOAST) criteria in ischemic stroke patients only; ${ }^{\dagger}$ Concentration subgroup only (total $n=179 ; 84.8 \%$ ); ${ }^{*}$ Estimated glomerular filtration rate according to Cockcroft-Gault formula; ${ }^{5}$ Ultraperformance liquid chromatography-tandem mass spectrometry. 
Supplementary Table 2. Differences between low and high DOAC exposure $(n=211)$

\begin{tabular}{|c|c|c|c|}
\hline Variable & $\begin{array}{l}\text { Low DOAC exposure (AUC }<0.5) \\
\qquad(n=133,63.0 \%)\end{array}$ & $\begin{array}{l}\text { High DOAC exposure (AUC } \geq 0.5) \\
\qquad(n=78,37.0 \%)\end{array}$ & Descriptive $P$ \\
\hline Female sex & 67 (50.4) & $40(51.3)$ & $0.899^{\ddagger}$ \\
\hline Age (yr) & $80(74-86)$ & $80(76-86)$ & $0.452^{\S}$ \\
\hline Body weight (kg) & $\begin{array}{l}75 \text { (65-85) } \\
124 \text { (93.2) }\end{array}$ & $\begin{array}{l}75 \text { (65-84) } \\
77(98.7)\end{array}$ & $0.977^{\S}$ \\
\hline Ischemic stroke & $107(80.5)$ & $50(64.1)$ & $0.014^{\dagger}$ \\
\hline TIA & $26(19.5)$ & $28(35.9)$ & \\
\hline Large vessel occlusion (ICA, MCA [1-3], PCA, ACA, BA) & $51(38.3)$ & $20(25.6)$ & $0.059^{*}$ \\
\hline Time of ischemic stroke/TIA (00:00-7:59)* & $24(18.0)$ & $21(26.9)$ & $0.129^{*}$ \\
\hline Time of ischemic stroke/TIA (8:00-15:59)* & $71(53.4)$ & $35(44.9)$ & $0.233^{\dagger}$ \\
\hline Time of ischemic stroke/TIA (16:00-23:59)* & $38(28.6)$ & $22(28.2)$ & $0.955^{+}$ \\
\hline \multicolumn{4}{|l|}{ Functional impairment } \\
\hline Admission NIHSS of patients with ischemic stroke & $7(3-18)$ & $5(2-11)$ & $0.020^{\S}$ \\
\hline Premorbid modified Rankin Scale & $2(0-3)$ & $1(0-3)$ & $0.353^{\S}$ \\
\hline Modified Rankin Scale at 3 months & $\begin{array}{r}3(1-5) \\
124(93.2)\end{array}$ & $\begin{array}{c}2(0-4) \\
75(96.2)\end{array}$ & $0.016^{5}$ \\
\hline \multicolumn{4}{|l|}{ Comorbidities } \\
\hline Arterial hypertension & $120(90.2)$ & 70 (89.7) & $0.910^{\dagger}$ \\
\hline Diabetes & 45 (33.8) & $23(29.5)$ & $0.514^{\dagger}$ \\
\hline Hypercholesterolemia & $74(55.6)$ & $45(57.7)$ & $0.772^{\ddagger}$ \\
\hline Previous stroke or TIA & 45 (33.8) & $29(37.2)$ & $0.623^{\neq}$ \\
\hline Congestive heart failure & $26(19.5)$ & $14(17.9)$ & $0.775^{\dagger}$ \\
\hline Vascular disease & $70(52.6)$ & $44(56.4)$ & $0.595^{*}$ \\
\hline Atrial fibrillation & $120(90.2)$ & $72(92.3)$ & $0.610^{*}$ \\
\hline Premorbid $\mathrm{CHA}_{2} \mathrm{DS}_{2}$-VASc score & $5(4-6)$ & $5(4-6)$ & $0.401^{\S}$ \\
\hline Creatinine at admission (mg/dL) & $0.89(0.75-1.13)$ & $0.98(0.78-1.16)$ & $0.658^{\S}$ \\
\hline eGFR $(\mathrm{mL} / \mathrm{min})^{+}$ & $\begin{array}{l}65.08(50.3-85.0) \\
107(80.5)\end{array}$ & $\begin{array}{l}56.27(43.0-77.0) \\
\quad 60(76.9)\end{array}$ & $0.081^{5}$ \\
\hline \multicolumn{4}{|l|}{ Pharmacotherapy } \\
\hline Apixaban & $62(46.6)$ & $17(21.8)$ & $<0.001^{\dagger}$ \\
\hline Edoxaban & $16(12.0)$ & $4(5.1)$ & $0.099^{\dagger}$ \\
\hline Rivaroxaban & $38(28.6)$ & $50(64.1)$ & $<0.001^{\dagger}$ \\
\hline Dabigatran & $17(12.8)$ & $7(9.0)$ & $0.400^{\ddagger}$ \\
\hline Additional antiplatelet therapy & $12(9.0)$ & $7(9.0)$ & $0.832^{\dagger}$ \\
\hline Time between last DOAC intake and admission (min) & $635(294-942)$ & $523(280-788)$ & $0.264^{\S}$ \\
\hline Time between DOAC intake and event $(\mathrm{min})^{*}$ & $\begin{array}{l}505 \text { (18-725) } \\
118 \text { (88.7) }\end{array}$ & $\begin{array}{l}450(235-645) \\
61(78.2)\end{array}$ & $0.138^{5}$ \\
\hline \multicolumn{4}{|l|}{ Prescription quality } \\
\hline DOAC adherence to SmPCs: underdosed & $38(28.6)$ & $13(16.7)$ & $0.051^{*}$ \\
\hline DOAC adherence to SmPCs: correctly dosed & $93(69.9)$ & $60(76.9)$ & $0.272^{\dagger}$ \\
\hline DOAC adherence to SmPCs: overdosed & $2(1.5)$ & $5(6.4)$ & $0.055^{\ddagger}$ \\
\hline
\end{tabular}

Values are presented as number (\%) or median (interquartile range).

DOAC, direct oral anticoagulant; AUC, area under the curve; TIA, transient ischemic attack; ICA, internal carotid artery; MCA (1-3), middle cerebral artery (segments 1-3); PCA, posterior cerebral artery; ACA, anterior cerebral artery; BA, basilar artery; NIHSS, National Institutes of Health Stroke Scale; eGFR, estimated glomerular filtration rate; $\mathrm{SmPC}$, recommended doses from summaries of product characteristic.

${ }^{*}$ Concentration subgroup only (total $\left.n=179 / 211 ; 84.8 \%\right) ;{ }^{+}$eGFR according to Cockcroft-Gault formula; ${ }^{\ddagger}$ Chi-square; ${ }^{5}$ t-test. 
Supplementary Table 3. Multivariate logistic regression between high and low DOAC exposure $(n=211)$

\begin{tabular}{lccc}
\hline \multirow{2}{*}{ Variable } & \multicolumn{3}{c}{ High vs. low DOAC exposure } \\
\cline { 2 - 4 } Creatinine at admission $(\mathrm{mg} / \mathrm{dL})$ & OR & $95 \% \mathrm{Cl}$ & 0.809 \\
Age & 0.905 & $0.398-2.074$ & 0.410 \\
Female sex & 0.985 & $0.949-1.020$ & 0.836 \\
DOAC adherence to SmPCs: overdosed & 0.936 & $0.499-1.759$ & 0.193 \\
DOAC adherence to SmPCs: underdosed & 0.327 & $0.046-1.586$ & 0.044 \\
\hline
\end{tabular}

DOAC, direct oral anticoagulant; $\mathrm{OR}$, odds ratio; $\mathrm{Cl}$, confidence interval; SmPC, recommended doses from summaries of product characteristic.

Supplementary Table 4. Multivariate logistic regression between patients with and without large vessel occlusions of all included patients and of patients with modeled DOAC concentration at the event

\begin{tabular}{|c|c|c|c|c|c|c|}
\hline \multirow{3}{*}{ Variable } & \multicolumn{6}{|c|}{ Large vessel occlusion vs. no large vessel occlusion* } \\
\hline & \multicolumn{3}{|c|}{$\begin{array}{l}\text { All included ischemic stroke patients } \\
\qquad(\mathrm{n}=157)^{+}\end{array}$} & \multicolumn{3}{|c|}{$\begin{array}{l}\text { Ischemic stroke patients with modeled DOAC concentration } \\
\text { at the event }(n=131)^{\dagger}\end{array}$} \\
\hline & $\mathrm{OR}$ & $95 \% \mathrm{Cl}$ & $P$ & $\mathrm{OR}$ & $95 \% \mathrm{Cl}$ & $P$ \\
\hline Low DOAC exposure ${ }^{\S}$ & 1.360 & $0.660-2.803$ & 0.404 & - & - & - \\
\hline Low DOAC concentration at event ${ }^{\S}$ & - & - & - & 0.619 & $0.287-1.335$ & 0.222 \\
\hline Female sex & 0.713 & $0.348-1.459$ & 0.354 & 0.763 & $0.350-1.663$ & 0.496 \\
\hline Age & 0.982 & $0.945-1.021$ & 0.364 & 0.965 & $0.923-1.009$ & 0.119 \\
\hline Hypertension & 0.496 & $0.158-1.557$ & 0.230 & 0.779 & $0.233-2.600$ & 0.685 \\
\hline Diabetes mellitus & 0.827 & $0.369-1.851$ & 0.644 & 1.174 & $0.467-2.948$ & 0.733 \\
\hline Hypercholesterolemia & 0.875 & $0.428-1.791$ & 0.716 & 0.768 & $0.349-1.689$ & 0.511 \\
\hline Previous stroke/TIA & 0.560 & $0.265-1.182$ & 0.128 & 0.568 & $0.256-1.261$ & 0.165 \\
\hline Congestive heart failure & 2.001 & $0.851-4.709$ & 0.112 & 2.468 & $0.912-6.683$ & 0.075 \\
\hline Vascular disease & 0.767 & $0.366-1.610$ & 0.484 & 0.693 & $0.305-1.574$ & 0.381 \\
\hline Atrial fibrillation & 1.216 & $0.374-3.957$ & 0.745 & 1.103 & $0.290-4.197$ & 0.885 \\
\hline
\end{tabular}

$\mathrm{DOAC}$, direct oral anticoagulant; $\mathrm{OR}$, odds ratio; $\mathrm{Cl}$, confidence interval; $\mathrm{TIA}$, transient ischemic attack.

${ }^{*}$ Internal carotid artery, middle cerebral artery (segments 1-3), posterior cerebral artery, anterior cerebral artery, or basilar artery; ${ }^{+}$No large vessel occlusion $(n=87)$, large vessel occlusion $(n=70) ;{ }^{*}$ No large vessel occlusion $(n=62)$, large vessel occlusion $(n=69) ;{ }^{5}$ Derived from normalized ratios with reference populations. 
Supplementary Table 5. Differences between low and high DOAC concentrations at onset of the event $(n=179)$

\begin{tabular}{|c|c|c|c|}
\hline Variable & $\begin{array}{l}\text { Low DOAC concentration } \\
\qquad(n=81,45.3 \%)\end{array}$ & $\begin{array}{l}\text { High DOAC concentration } \\
(n=98,54.7 \%)\end{array}$ & Descriptive $P$ \\
\hline Female sex & $43(53.1)$ & $51(52.0)$ & $0.889^{+}$ \\
\hline Age (yr) & $78(72-86)$ & $81(77-86)$ & $0.019^{\ddagger}$ \\
\hline Body weight (kg) & $\begin{array}{l}75(68-85) \\
75(92.6)\end{array}$ & $\begin{array}{l}75(65-83) \\
94(95.9)\end{array}$ & $0.247^{*}$ \\
\hline Ischemic stroke & $69(85.2)$ & $62(63.3)$ & $0.001^{+}$ \\
\hline TIA & $12(14.8)$ & $36(36.7)$ & \\
\hline Large vessel occlusion (ICA, MCA [1-3], PCA, ACA, BA) & $33(40.7)$ & $37(37.8)$ & $0.684^{+}$ \\
\hline Time of ischemic stroke/TIA (00:00-7:59) & $13(16.0)$ & $20(20.4)$ & $0.454^{+}$ \\
\hline Time of ischemic stroke/TIA (8:00-15:59) & $49(60.5)$ & $45(45.9)$ & $0.052^{+}$ \\
\hline Time of ischemic stroke/TIA (16:00-23:59) & $19(23.5)$ & $33(33.7)$ & $0.134^{+}$ \\
\hline \multicolumn{4}{|l|}{ Functional impairment } \\
\hline Admission NIHSS of patients with ischemic stroke & $8(4-19)$ & $9(3-16)$ & $0.755^{*}$ \\
\hline Premorbid modified Rankin Scale & $1(0-3)$ & $1(0-3)$ & $0.965^{\dagger}$ \\
\hline Modified Rankin Scale at 3 months & $\begin{array}{r}3(1-6) \\
74(91.4)\end{array}$ & $\begin{array}{r}3(1-5) \\
96(98.0)\end{array}$ & $0.111^{\ddagger}$ \\
\hline \multicolumn{4}{|l|}{ Comorbidities } \\
\hline Arterial hypertension & $73(90.1)$ & 86 (87.8) & $0.617^{+}$ \\
\hline Diabetes & $31(38.3)$ & $25(25.5)$ & $0.067^{+}$ \\
\hline Hypercholesterolemia & $45(55.6)$ & $56(57.1)$ & $0.831^{+}$ \\
\hline Previous stroke or TIA & $30(37.0)$ & $31(31.6)$ & $0.448^{+}$ \\
\hline Congestive heart failure & $14(17.3)$ & $20(20.4)$ & $0.596^{+}$ \\
\hline Vascular disease & $41(50.6)$ & $53(54.1)$ & $0.644^{+}$ \\
\hline Atrial fibrillation & $73(90.1)$ & $90(91.8)$ & $0.689^{+}$ \\
\hline Premorbid $\mathrm{CHA}_{2} \mathrm{DS}_{2}$-VASc score & $5(4-6)$ & $5(4-6)$ & $0.898^{\ddagger}$ \\
\hline Creatinine at admission $(\mathrm{mg} / \mathrm{dL})$ & $0.87(0.75-1.12)$ & $0.96(0.80-1.14)$ & $0.227^{*}$ \\
\hline eGFR $(\mathrm{mL} / \mathrm{min})^{*}$ & $\begin{array}{l}69.9(52.7-86.8) \\
75(92.6)\end{array}$ & $\begin{array}{l}56.9(44.0-78.4) \\
92(93.9)\end{array}$ & $0.006^{\ddagger}$ \\
\hline \multicolumn{4}{|l|}{ Pharmacotherapy } \\
\hline Apixaban & $23(28.4)$ & $44(44.9)$ & $0.023^{+}$ \\
\hline Edoxaban & 11 (13.6) & $5(5.1)$ & $0.048^{+}$ \\
\hline Rivaroxaban & $35(43.2)$ & $43(43.9)$ & $0.929^{+}$ \\
\hline Dabigatran & $12(14.8)$ & $6(6.1)$ & $0.054^{+}$ \\
\hline Additional antiplatelet therapy & $10(12.3)$ & $9(9.2)$ & $0.541^{+}$ \\
\hline Time between last DOAC intake and admission (min) & $895(557-1,295)$ & $507(320-723)$ & $<0.001^{+}$ \\
\hline Time between DOAC intake and event ( $\mathrm{min})$ & $660(345-1,043)$ & $383(180-570)$ & $<0.001^{\ddagger}$ \\
\hline \multicolumn{4}{|l|}{ Prescription quality } \\
\hline DOAC adherence to SmPCs: underdosed & $25(30.9)$ & $21(21.4)$ & $0.150^{+}$ \\
\hline DOAC adherence to SmPCs: correctly dosed & $54(66.7)$ & $72(73.5)$ & $0.321^{+}$ \\
\hline DOAC adherence to SmPCs: overdosed & $2(2.5)$ & $5(5.1)$ & $0.366^{\dagger}$ \\
\hline
\end{tabular}

Values are presented as number (\%) or median (interquartile range).

DOAC, direct oral anticoagulant; TIA, transient ischemic attack; ICA, internal carotid artery; MCA (1-3), middle cerebral artery (segments 1-3); PCA, posterior cerebral artery; ACA, anterior cerebral artery; BA, basilar artery; NIHSS, National Institutes of Health Stroke Scale; eGFR, estimated glomerular filtration rate; $\mathrm{SmPC}$, recommended doses from summaries of product characteristic.

${ }^{*}$ eGFR according to Cockcroft-Gault formula; ${ }^{+}$Chi-square; ${ }^{*}$ t-test. 
Supplementary Table 6. Differences between favorable and unfavorable 3 months outcome in ischemic stroke patients $(n=149)$

\begin{tabular}{|c|c|c|c|}
\hline Variable & $\begin{array}{c}\text { 3-month mRS 0-2 } \\
(n=57,38.3 \%)\end{array}$ & $\begin{array}{c}\text { 3-month mRS 3-6 } \\
(n=92,61.7 \%)\end{array}$ & Descriptive $P$ \\
\hline Female sex & $24(42.1)$ & $53(57.6)$ & $0.066^{\dagger}$ \\
\hline Age (yr) & $76(72-81)$ & $82(76-87)$ & $<0.001^{\S}$ \\
\hline Body weight $(\mathrm{kg})$ & $\begin{array}{l}80(69-90) \\
57(100)\end{array}$ & $\begin{array}{l}74(65-82) \\
87(94.6)\end{array}$ & $0.002^{\S}$ \\
\hline Large vessel occlusion (ICA, MCA [1-3], PCA, ACA, BA) & $24(42.1)$ & 45 (48.9) & $0.418^{\ddagger}$ \\
\hline Recanalisation therapy & $22(38.6)$ & $34(37.0)$ & $0.841^{\dagger}$ \\
\hline Time of ischemic stroke (00:00-07:59)* & $8(18.6)$ & $13(15.9)$ & $0.696^{5}$ \\
\hline Time of ischemic stroke (8:00-15:59)* & $22(51.2)$ & $47(57.3)$ & $0.511^{\S}$ \\
\hline Time of ischemic stroke (16:00-23:59)* & $13(30.2)$ & $22(26.8)$ & $0.687^{\S}$ \\
\hline \multicolumn{4}{|l|}{ Functional impairment } \\
\hline Admission NIHSS & $3(1-7)$ & $11(5-19)$ & $<0.001^{\S}$ \\
\hline Premorbid mRS & $1(0-1)$ & $3(1-3)$ & $<0.001^{\S}$ \\
\hline \multicolumn{4}{|l|}{ Comorbidities } \\
\hline Arterial hypertension & $53(93.0)$ & $81(88.0)$ & $0.330^{\dagger}$ \\
\hline Diabetes & $13(22.8)$ & $31(33.7)$ & $0.157^{+}$ \\
\hline Hypercholesterolemia & $33(57.9)$ & $46(50.0)$ & $0.348^{\ddagger}$ \\
\hline Previous stroke or TIA & $15(26.3)$ & $33(35.9)$ & $0.225^{+}$ \\
\hline Congestive heart failure & $13(22.8)$ & $19(20.7)$ & $0.756^{\ddagger}$ \\
\hline Vascular disease & 29 (50.9) & $50(54.3)$ & $0.680^{\dagger}$ \\
\hline Atrial fibrillation & $52(91.2)$ & $85(92.4)$ & $0.800^{\dagger}$ \\
\hline Premorbid $\mathrm{CHA}_{2} \mathrm{DS}_{2}$-VASc score & $4(3-6)$ & $5(4-6)$ & $0.009^{\S}$ \\
\hline Creatinine at admission (mg/dL) & $0.88(0.74-1.10)$ & $0.94(0.73-1.15)$ & $0.537^{\S}$ \\
\hline $\mathrm{eGFR}(\mathrm{mL} / \mathrm{min})^{+}$ & $\begin{array}{l}67.56(56.4-82.2) \\
\quad 43(75.4)\end{array}$ & $\begin{array}{l}59.24(41.6-82.1) \\
\quad 76(82.6)\end{array}$ & $0.018^{\S}$ \\
\hline \multicolumn{4}{|l|}{ Pharmacotherapy } \\
\hline Time between last DOAC intake and admission (min) & $496(249-869)$ & $650(409-952)$ & $0.162^{\S}$ \\
\hline Time between DOAC intake and event $(\mathrm{min})^{*}$ & $420(180-720)$ & $480(236-698)$ & $0.035^{\S}$ \\
\hline Low DOAC exposure & $36(63.2)$ & $65(70.7)$ & $0.341^{*}$ \\
\hline Low DOAC concentration at event* & $22 / 43(51.2)$ & $42 / 82(51.2)$ & $0.995^{+}$ \\
\hline Non-adherence & $4(7.0)$ & $12(13.0)$ & $0.031^{\ddagger}$ \\
\hline \multicolumn{4}{|l|}{ Prescription quality } \\
\hline DOAC adherence to SmPCs: underdosed & $13(22.8)$ & 27 (29.3) & $0.381^{\dagger}$ \\
\hline DOAC adherence to SmPCs: correctly dosed & $43(75.4)$ & $61(66.3)$ & $0.238^{\ddagger}$ \\
\hline DOAC adherence to SmPCs: overdosed & $1(1.8)$ & $4(4.3)$ & $0.393^{\dagger}$ \\
\hline
\end{tabular}

Values are presented as number (\%) or median (interquartile range).

mRS, modified Rankin Scale; ICA, internal carotid artery; MCA (1-3), middle cerebral artery (segments 1-3); PCA, posterior cerebral artery; ACA, anterior cerebral artery; BA, basilar artery; NIHSS, National Institutes of Health Stroke Scale; TIA, transient ischemic attack; eGFR, estimated glomerular filtration rate; DOAC, direct oral anticoagulant; SmPC, recommended doses from summaries of product characteristic.

${ }^{*}$ Concentration subgroup only $(n=125) ;{ }^{+}$eGFR according to Cockcroft-Gault formula; ${ }^{\dagger}$ Chi-square; ${ }^{5}$ t-test. 
Supplementary Table 7. Multivariate logistic regression between favorable and unfavorable 3 months outcome in ischemic stroke patients with follow-up information $(n=149)$

\begin{tabular}{|c|c|c|c|}
\hline & \multicolumn{3}{|c|}{ Favorable (mRS 0-2) vs. unfavorable (mRS 3-6) 3 months outcome ( $n=149$ ) } \\
\hline & $\mathrm{OR}$ & $95 \% \mathrm{Cl}$ & $P$ \\
\hline Age (yr) & 1.034 & $0.955-1.120$ & 0.413 \\
\hline Body weight (kg) & 0.986 & $0.944-1.029$ & 0.515 \\
\hline Admission NIHSS & 1.174 & $1.079-1.278$ & $<0.001$ \\
\hline Premorbid mRS & 2.881 & $1.720-4.828$ & $<0.001$ \\
\hline Premorbid $\mathrm{CHA}_{2} \mathrm{DS}_{2}$-VASc score & 0.861 & $0.589-1.260$ & 0.442 \\
\hline eGFR $(\mathrm{mL} / \mathrm{min})^{*}$ & 1.009 & $0.981-1.038$ & 0.522 \\
\hline Time between DOAC intake and event (min) & 0.999 & $0.998-1.000$ & 0.196 \\
\hline Non-adherence & 0.774 & $0.106-5.633$ & 0.800 \\
\hline Atrial fibrillation & 0.647 & $0.075-5.572$ & 0.692 \\
\hline
\end{tabular}

mRS, modified Rankin Scale; OR, odds ratio; $\mathrm{Cl}$, confidence interval; NIHSS, National Institutes of Health Stroke Scale; eGFR, estimated glomerular filtration rate; $\mathrm{DOAC}$, direct oral anticoagulant.

*eGFR according to Cockcroft-Gault formula.

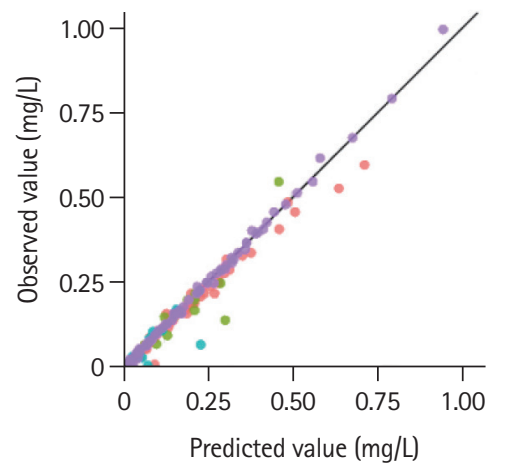

A

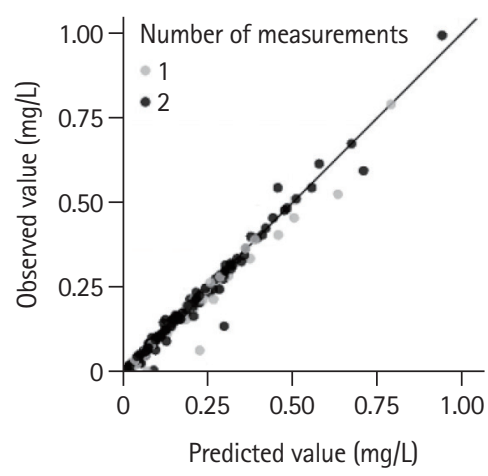

C

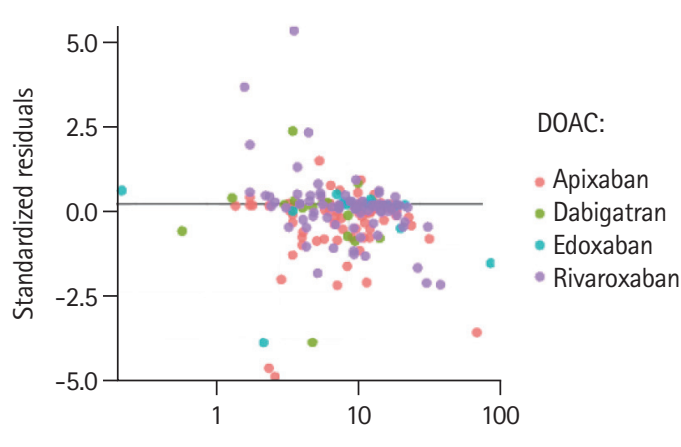

Time after administration (hr)

B

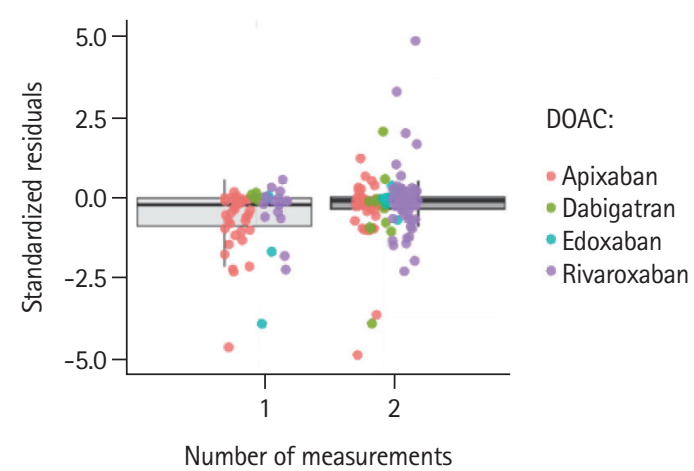

(D)

Supplementary Figure 1. Diagnostic plots to explore deviations of predicted concentrations from observed measurements at the respective times of measurement. $(A, C)$ Panels visualize the bivariate relationship between predicted concentrations und observed measurements with distinct pairs of values colour-coding individual direct oral anticoagulants (DOACs) or whether the indicator was derived from a pharmacokinetic profile estimated by one or two measurements per patient. Residual plots illustrate residuals over time after the last DOAC administration (B) or residuals stratified by their origin from pharmacokinetic profiles with one-point or two-point estimation (D). 

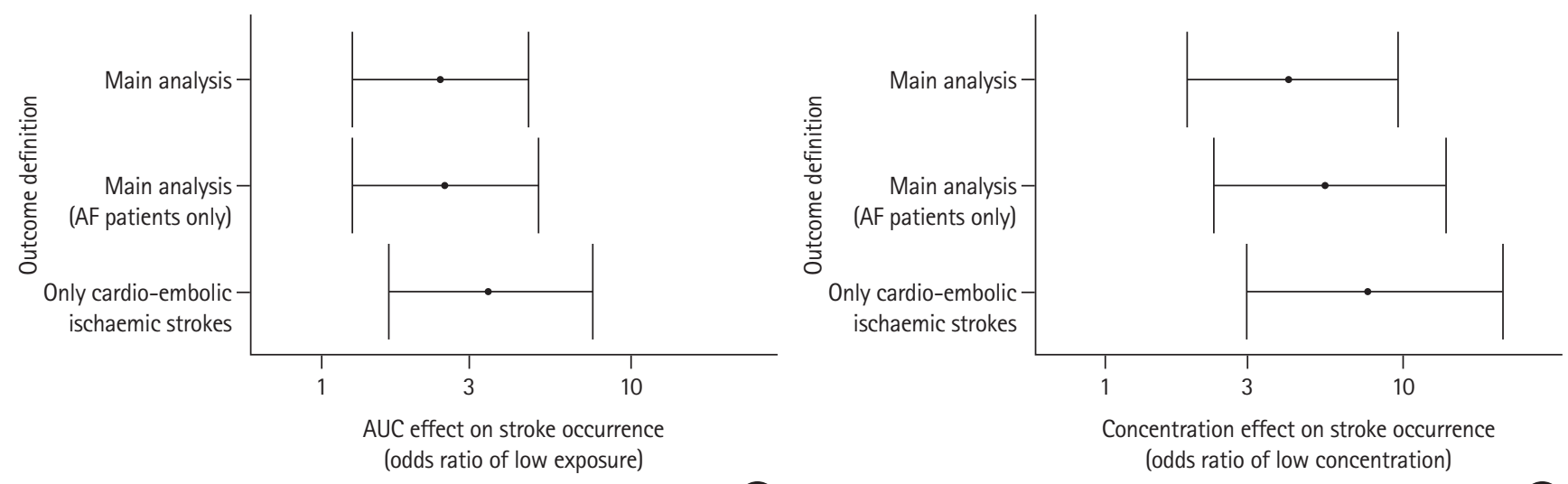

A

Supplementary Figure 2. Forest plot of effect estimates (expressed as odds ratios) of either low direct oral anticoagulant (DOAC) plasma exposure (A) or low DOAC plasma concentration at the time of the event (B) on the risk of ischemic stroke. Different outcome definitions are plotted on the discrete $y$-axis with the results from the main analysis, a restricted sample including only patients with atrial fibrillation (AF), and a sample including only cardioembolic ischemic strokes. Whiskers around the point estimates visualize 95\% confidence intervals. AUC, area under the curve.

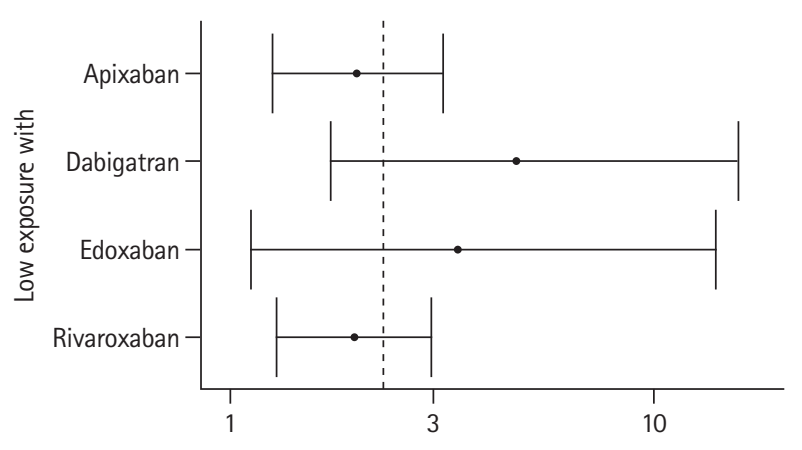

Odds ratio for stroke occurrence

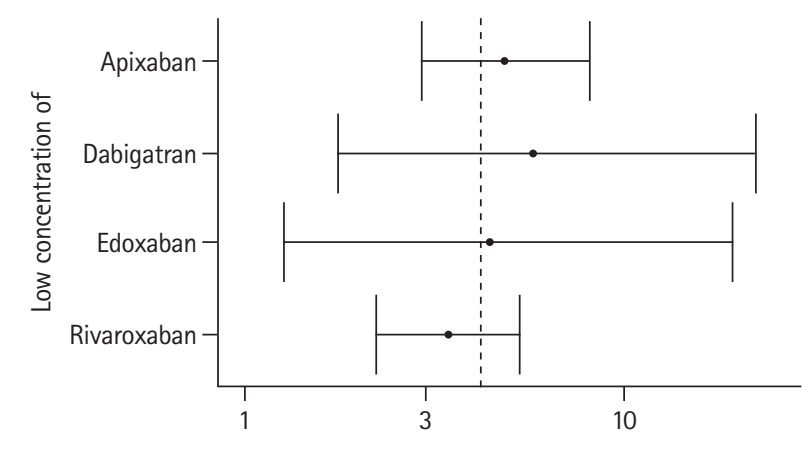

Odds ratio for stroke occurrence

A
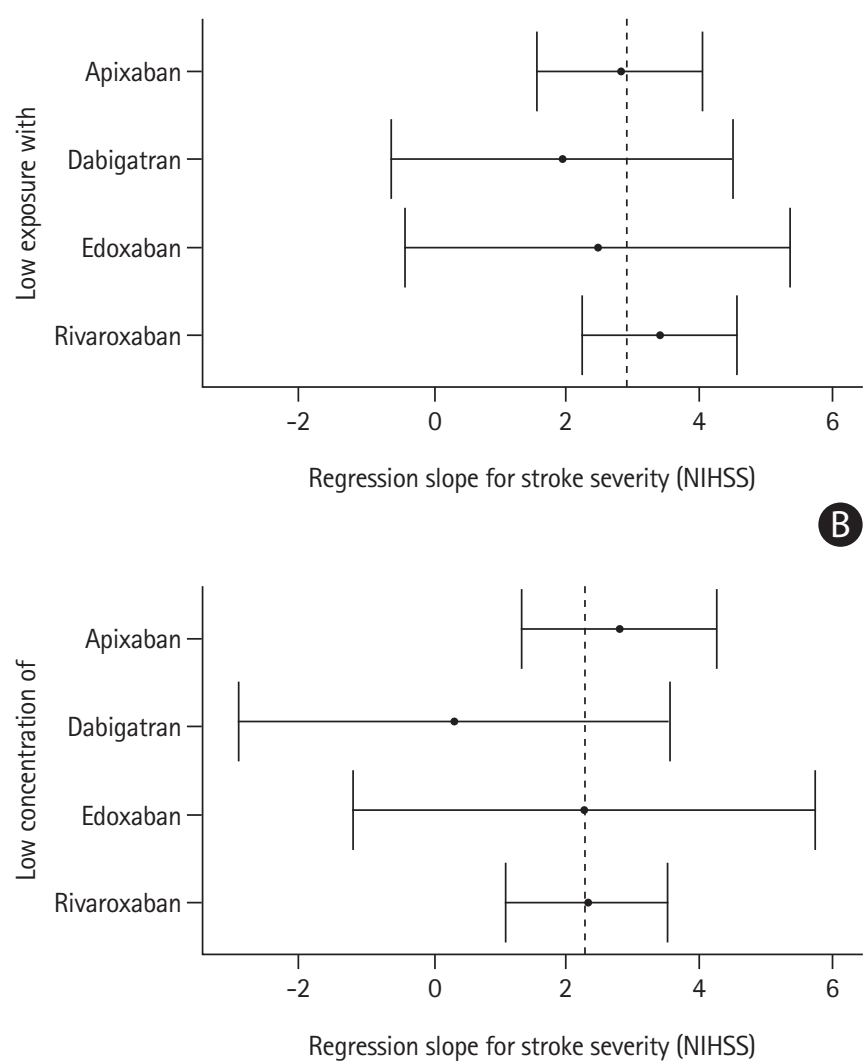

(D)

Supplementary Figure 3. Substance-specific modulation of overall direct oral anticoagulant (DOAC) effects expressed as odds ratio for the probability of stroke occurrence (left side, A, C) or as a linear increase in the National Institutes of Health Stroke Scale (NIHSS) score for stroke severity (right side, B, D). The top row indicates substance-specific effects around the DOAC class effect (dashed vertical line) in terms of exposure (area under the curve [AUC]), while the bottom row indicated substance-specific effects in term of concentration at the time of the event. Whiskers visualize $95 \%$ confidence intervals of the respective estimates. 